\title{
Diálogos y reflexiones sobre las comunicaciones en la Unidad Popular. Chile, 1970-1973
}

\author{
Carla RiverA ARAVENA \\ Universidad de Santiago de Chile \\ cariver2@uc.cl
}

Recibido: 9 de septiembre de 2015

Aceptado: 15 de noviembre de 2015

\begin{abstract}
Resumen
El siguiente artículo analiza el debate que se gestó en torno a las comunicaciones durante la Unidad Popular. El Centro de Estudios de la Realidad Nacional (CEREN), de la Universidad Católica de Santiago, sentó un precedente en la constitución de nuevas propuestas -distintas a las dominantes- que posteriormente se transformaron en paradigmas de las comunicaciones. Armand Mattelart, Michèle Mattelart y Mabel Piccini, de hecho, abrieron el debate evidenciando y cuestionando la falta de visión de la izquierda en la materia. La falta de políticas comunicacionales emanadas desde el gobierno, de este modo, no impidió el desarrollo de nuevas experiencias en función del contexto revolucionario.
\end{abstract}

Palabras clave: Unidad Popular; Comunicación Revolucionaria; Centro de Estudios de la Realidad Nacional; Armand Mattelart; Michèle Mattelart y Mabel Piccini.

\section{Dialogs and reflections on the communications in the Unidad Popular. Chile, 1970-1973}

\begin{abstract}
The following article examines the debate that aroused concerning communications during the government of Popular Unity. The Center of Studies of the National Reality (CEREN), of the Catholic University of Santiago, established a precedent proposing new approaches - different to the dominant ones - that were later transformed into paradigms for Communications. Armand Mattelart, Michèle Mattelart and Mabel Piccini, in fact, opened the debate demonstrating and questioning the lack of vision of the left in this matter. Thus the lack of communication policies from the government did not prevent the development of new experiences conditioned by the revolutionary context.
\end{abstract}

Keywords: Unidad Popular; Revolutionary Communications; Center for Studies of the National Reality; Armand Mattelart; Michèle Mattelart y Mabel Piccini.

\section{Referencia normalizada}

Rivera Aravena, C. (2015). Diálagos y reflexiones sobre las comunicaciones en la Unidad Popular. Chile, 1970-1973. Historia y Comunicación Social. Vol 20, número 2, páginas 345-367.

Sumario: 1. Introducción. 2. Construir un Bello Caos. La Reforma en la Universidad Católica y el Nacimiento del Centro de Estudios de la Realidad Nacional (CEREN). 3. El CEREN. Un espacio para la manifestación de pensamiento crítico. 4. Pensar las Comunicaciones Revolucionarias. Tensiones y ruptura entre la experticia académica y las directrices políticas. 5. Conclusion. 6. Referencias bibliográficas. 


\section{Introducción}

Desde el golpe militar de 1973, la mayoría de los medios de comunicación se vieron silenciados por las políticas implementadas por la Junta. Todos los soportes comunicacionales - principalmente la prensa escrita y la radio- fueron clausurados y expropiados ilegalmente. Con estas medidas se inició el proceso de desmantelamiento que afectó principalmente a aquellos medios asociados a los partidos políticos o a posturas de izquierda vinculadas a la Unidad Popular, poniendo fin a la forma en que se había desarrollado históricamente el sistema de comunicación y la opinión pública en el país. Para Augusto Pinochet, los medios de comunicación tuvieron un papel protagónico en el fracaso del gobierno de Allende, y él, en su calidad de máxima autoridad, no estaba dispuesto a experimentar la misma situación. Las constantes represiones, que incluso se ejercieron en forma de castigo físico a los periodistas, obligaron a los medios a establecer distintos mecanismos para autoprotegerse, los cuales frenaron el libre acceso a la información (Rivera, 2008). ${ }^{1}$

Distintos especialistas de las ciencias sociales y de las comunicaciones han reflexionado, desde el estudio de los mensajes que circularon en las emisiones de radio, televisión y prensa, sobre el "protagonismo" o el grado de responsabilidad de éstos en la crisis política del período. Dooner (1985), Bernedo y Porath (2003-2004) concuerdan al señalar que el error de los medios de comunicación de masas fue participar en el conflicto político-social del período, transgrediendo la labor profesional del periodismo; es decir, "la de informar veraz y objetivamente los hechos de la realidad". Para otros investigadores, en cambio, las prácticas comunicacionales respondían a su contexto histórico, ya sea como instrumento activo para la lucha política y el conflicto ideológico (Santa Cruz, 2014; Sunkel, 1983), o como mediadores pasivos que solo reflejaron el momento que atravesaba el país (Fermandois, 2013). En síntesis, los trabajos expuestos evidencian la tensión permanente sobre el sentido de las comunicaciones, vale decir, la frontera entre ser simplemente un narrador o un actor de conflicto; excluyendo de la reflexión el análisis general sobre el funcionamiento del sistema comunicacional en un proyecto político que se instala en el escenario nacional y mundial como único.

En efecto, Paulina Gutiérrez, Giselle Munizaga y Alfredo Riquelme constatan que el sistema de comunicación desde el gobierno de Frei Montalva (1964-1970) hasta el golpe de 1973, se mantuvo sin modificaciones sustanciales que desviaran su carácter o sentido (1985:214), ya que las medidas que se adoptaron estuvieron delimitadas por la lucha interna para aumentar la presencia o el control sobre los medios de cada grupo en pugna. ${ }^{2}$ De esta manera, señalan, las tácticas que se desplegaron por los sectores de izquierda no lograron ser representativas de las líneas de acción que buscaban desarrollarse en y por la Vía Chilena al Socialismo (Mattelart, M., 1976). Por lo tanto, cabe preguntarse: ¿qué proyecto de comunicaciones desarrolló la Unidad Popular acorde al propósito político que se quería alcanzar? En otras palabras, ¿hubo estrategias comunicacionales propiamente revolucionarias? 
Desde un inicio, la Unidad Popular manifestó interés y preocupación por las comunicaciones. El Programa Básico de la Unidad Popular, de hecho, destacó su importancia pedagógica en la formación de una Nueva Cultura, por lo que era de suma importancia liberarlos de su criterio comercial (Programa Básico de la Unidad Popular, 1969). Sin embargo, los procesos políticos, económicos y socio-comunicativos del periodo impidieron el desarrollo de políticas de comunicación efectivas; entendiendo que estas políticas implican "acciones explícitas, planificadas y participativas que se generan en espacios socioculturales específicos y que implican, de manera integral, pero no excluyente, aspectos: (a) legislativos, (b) políticos, (c) económicos, (d) socioculturales y (e) territoriales" (Del Valle, 2005: 1). Efectivamente, los amarres legislativos que se instalaron con la firma de los Estatutos Constitucionales y la falta de consenso dentro de la izquierda para levantar un Frente Cultural consistente (Fernández, 2003, Bowen, 2006), obstaculizaron el desarrollo de comunicaciones desde el gobierno acordes a las necesidades del periodo. No obstante, esta situación no inhabilitó el desarrollo de nuevas propuestas y experiencias comunicativas, capaces de proponer nuevas estructuras de medios con posibilidades reales de participación popular, desde espacios en donde la convergencia de la ciencia, la cultura y la política eran posible: las universidades.

Con el inicio de los procesos de reformas universitarias en la segunda mitad de los sesenta, las universidades asumieron como misión formar y producir conocimiento en relación a las necesidades del país. Para ello se crearon centros de investigación interdisciplinarios con el propósito de conocer y producir conocimiento de, para y con la sociedad. Los encargados por antonomasia fueron los científicos sociales, quienes, además de producir una imagen general de la sociedad y un diagnóstico de la totalidad, debían proponer modelos alternativos para su re-estructuración (Garretón,1982, Vasconi, 1991; Brunner, Flisfisch, 1983; Beigel, 2011, Lozoya, 2013).

Desde este prisma, la Universidad Católica de Santiago destacó del resto de las universidades nacionales por el papel que adquirieron las comunicaciones en su proyecto reformista. ${ }^{3}$ Es decir, además de instalarse como un área de saber, se utilizó a las comunicaciones como articulador teórico transversal de vinculación de la institución consigo misma y con el exterior. Se creó la Vicerrectoría de Comunicaciones, distintos centros académicos con áreas de especialización en comunicaciones y cultura como el Centro de Estudios de la Realidad Nacional (CEREN) y la Escuela de Artes y Comunicaciones (EAC), el Centro de Cultura Popular y Talleres Experimentales de Prensa Popular creados por el Centro de Alumnos de Periodismo, con el propósito de establecer una relación recíproca y dialógica entre el cuerpo académico y la sociedad, el saber y el hacer. Si bien cada unidad académica diseñó distintas estrategias docentes en base a este eje, ninguno impactó en el espacio público como el CEREN, al punto que en 1971 el presidente Salvador Allende convocó a los académicos Armand y Michèle Mattelart y Mabel Piccini a participar como asesores comunicacionales en la Editorial Quimantú y Televisión Nacional.

El siguiente artículo propone identificar y examinar los debates sobre el rol de la Comunicación en la Vía Chilena al Socialismo, entre el Centro de Estudios de la 
Realidad Nacional y la izquierda. El contacto entre estos intelectuales comprometidos con el proyecto político de la Unidad Popular permitió construir los pilares para el desarrollo de comunicaciones alternativas, también denominadas revolucionarias, ${ }^{4}$ capaces de transformar los principios de organización social hegemónicos en función de la Transición Chilena al Socialismo.

\section{Construir un Bello Caos. La Reforma en la Universidad Católica y el Naci- miento del Centro de Estudios de la Realidad Nacional (CEREN)}

Las tensiones y demandas sociales que marcaron los años sesenta también se hicieron sentir en los espacios académicos. La imposibilidad de cubrir la progresiva demanda de matrículas, además de la falta de investigación científica y formación profesional, daban una clara señal del atraso de las universidades nacionales (Dooner, Lavados, 1979). De esta manera, su modernización se volvió prioritaria para las autoridades universitarias y el Estado. La velocidad y el nivel de transformación que asumió cada centro de estudio fue resultado de la toma de conciencia de este proceso (Huneeus, 1988: 42).

En este escenario, la Universidad Católica -una de los centros de estudios superiores privados más antiguas (1888)- inició un proceso de modernización impulsado por factores tanto internos como externos. $\mathrm{Al}$ aumento de cupos y carreras, se sumó la renovación del pensamiento católico y los movimientos juveniles del período, todos los cuales asumieron un rol protagónico en los procesos de transformación social (Garretón y Martínez, 1987; Brunner, 1988; Huneeus, 1988). ${ }^{5}$

En 1959, la Federación de Estudiantes de la Universidad Católica (FEUC) pasó a manos de una directiva integrada por jóvenes militantes de la Democracia Cristiana, que -a diferencia de las dirigencias anteriores- imprimieron al movimiento estudiantil una visión del mundo distinta a la que promulgaba la tradicional misión de la universidad, esto es, "la imagen de un proceso formativo [...] (que) apuntaba hacia el ideal de una integración cristiana de la enseñanza, de donde se seguía que la Universidad Católica debía ser parte y prolongación de la Iglesia en el ámbito de la cultura superior" (Brunner, 1988: 269), por una de corte humanista, en la cual se destacaba "la vocación del estudiante en términos de un aprendizaje auténticamente universitario" (Krebs, 1994: 626) y el compromiso con la comunidad nacional, principalmente con los pobres (Federación de Estudiantes de la Universidad Católica, 1962). Como señaló el presidente de la FEUC, Manuel Antonio Garretón, en la VI Convención Ordinaria de Estudiantes de la Universidad Católica

El planteamiento académico hoy es una tarea transcendental para nuestra Universidad, por cuanto éste no significa simplemente reagrupación de lo que ya se tiene, sino fundamentalmente definición de lo que la Universidad [...] debe ser, definición que debe llevar a una revisión de lo que ya existe, a abandonar lo inservible por tradicional que sea y a crear una nueva mentalidad que informe una nueva estructura y nuevas tareas y actividades. Esta tarea que requiere profundidad y compromiso 
de todos los sectores universitarios, reviste carácter de extraordinaria urgencia -lo que no significa precipitación- dada la crisis por la que pasan las Universidades y la trascendencia de sus cambios para la sociedad global, es decir, para Chile" $(1964,54)$

El triunfo de la Democracia Cristiana (DC) en las urnas en 1964 reforzó la inquietud social de los estudiantes y, asimismo, tensionó las relaciones al interior del catolicismo. Al igual que la izquierda, la DC planteó un ideario que llamaba a subvertir el orden establecido por el desarrollo capitalista, con el fin de transformar las condiciones de vida de todos los chilenos a través de una economía de tipo comunitario y de sentido humano, una sociedad fraternal y no clasista (Partido Demócrata Cristiano, 1960).

Frente a los cambios, tanto globales como locales, los universitarios comenzaron a reformular su quehacer estudiantil y a exigir una mayor participación en los procesos internos. Los debates y reflexiones que se suscitaron principalmente en el Instituto de Sociología (1958) de la Universidad Católica con la participación de docentes como Franz Hinkelammert, Armand Mattelart, el jesuita Gonzalo Arroyo, Ernani Maria Fiori entre otros, consolidaron el compromiso de los estudiantes adscritos a la Juventud Demócrata Cristiana (JDC) y a la Acción de Universitarios Cristianos (AUC) con la militancia social católica (Beigel, 80-92) ${ }^{6}$. Frente a las negaciones y atrasos en el cumplimiento de los petitorios realizados por la FEUC, la mañana del once de agosto de 1967, la Sede Central de la Universidad amaneció tomada por los estudiantes, dando inicio al proceso de reforma. La comunidad de estudiantes y docentes tenían claro que había que replantear el sentido de la universidad; es decir, democratizarla y vincularla al acontecer histórico, pues era un agente social relevante en el proceso de cambio que la nación experimentaba.

En este escenario, la organización académica se planteó como un objetivo de carácter urgente ya que las carencias académicas, esto es, la falta de estamento docente y políticas de desarrollo en el área de la investigación, ponía en evidencia la falta de institucionalización universitaria. La primera medida que se adoptó consistió en crear departamentos, institutos, escuelas y centros. Estos últimos eran "organismos académicos de trabajo interdisciplinario que abordan la investigación y la docencia en un área de problemas de especial relevancia científica y social" (Vicerrectoría Académica, 1970: 92). Se crearon varios centros en función de las necesidades del país: Centro de Planificación Nacional (CEPLAN), Centro de Estudios Cooperativos (CEDUC), Centro de Ciencias de la Computación (CECICO), Centro de Estudios de la Realidad Nacional (CEREN), Centro de Desarrollo Urbano y Regional (CIDU) y Centro de Estudios Agrarios (CEA). La rapidez con que se crearon dejó en evidencia su importancia, pues eran los encargados de vincular la Universidad con la comunidad nacional. Es decir, un lugar de encuentro que permitiera construir "un horizonte de reciprocidad de cada hombre con los hombres del mundo" (Martín-Barbero, 2002: 31)

De esta manera, se levantaron los fundamentos de una importante reforma académica que consideró la creación de institutos disciplinarios y centros interdisciplinarios con un fuerte énfasis en investigación, más allá de la docencia, realizada en las 
facultades y escuelas. Se promovió la flexibilidad curricular para dar a los estudiantes la oportunidad de una formación académica más acorde con sus intereses diversos. En pocas palabras, la Universidad Católica se había transformado -en palabras de su Vicerrector Académico y uno de los creadores del proyecto educativo, el filósofo brasileño Ernani Maria Fiori- en un bello caos (Becca et. al., 2013: 1028).

\section{EI CEREN. Un espacio para la manifestación de pensamiento crítico}

Meses antes de la promulgación del Decreto de Rectoría No.134, que dio origen al Centro de Estudios de la Realidad Nacional, un grupo de académicos del Instituto de Sociología de la Universidad Católica, vinculados al Instituto de Capacitación y de Investigaciones para la Reforma Agraria (ICIRA) y comprometidos con los proyectos de cambio social desde la teoría crítica, vieron en la Reforma la posibilidad de construir un centro académico de investigación sobre la realidad nacional. En Abril de 1968, Franz Hinkelammert, Armand Mattelart, Jacques Chonchol y Andrés Pascal, presentaron al nuevo Rector la propuesta de una unidad académica que sintetizaba los nuevos objetivos de la Universidad, es decir, desarrollar una formación amplia, humanista y participativa, a través de un programa interdisciplinario, dedicado a la docencia y a la investigación de la realidad nacional (Chonchol, 1969). ${ }^{7}$ Gracias a la legitimidad que detentaban los especialistas como "intelectuales comprometidos con las transformaciones sociales del país", así como también debido a las relaciones familiares y de amistad que existían entre Fernando Castillo y el equipo, el CEREN pudo comenzar a funcionar antes de la promulgación oficial, y el 4 de noviembre de 1968 se instaló en la Universidad Católica como un centro académico estandarte de la Reforma, encargado de diseñar y aplicar programas educativos interdisciplinarios, acorde a los desafíos y necesidades nacionales. Para ello, se establecieron dos líneas de acción: la académica, cuyo propósito fue la investigación y docencia a partir de los problemas país, y la difusión de conocimiento con y en la sociedad.

Desde un inicio, el CEREN se caracterizó por asumir una posición crítica frente al desarrollismo, desde distintas lecturas de la filosofía social-cristiana y marxista que se encontraban insertas en la tradición socialista. ${ }^{8}$ La diversidad de miradas - muchas de ellas de avanzada en relación al manejo teórico de la izquierda tradicional que seguía atrapada en un marxismo ortodoxo- fue fruto de las redes intelectuales a las que estuvieron expuestos desde sus inicios los profesionales. ${ }^{9}$ Sin embargo, no es posible dar cuenta de una unidad teórica o principio vector en los discursos de los especialistas que formaban parte del centro, como si ocurría en otras organizaciones vinculadas a la tarea académica y de investigación social. El equipo directivo consideraba, de hecho, que la falta de enfoque común no era una limitación para el desarrollo de las investigaciones, ya que estaban seguros que la diversidad teórica era la única capaz de ofrecer una perspectiva más amplia sobre los procesos sociales, sentando las bases para "construir progresivamente una problemática global del cambio a partir de áreas o esferas particulares" (Garretón, 1971:7). La convergencia teórica que se 
gestó a partir de esa diversidad, permitió que el Centro se instalara como un espacio interdisciplinario, abierto al diálogo con distintos campos del saber e impidió la imposición de matrices que terminaran por encapsular las miradas sobre la realidad nacional. Sin embargo, frente a esta diversidad se puede constatar la preeminencia de un elemento de articulación transversal relevante en su constitución identitaria: la reflexión sobre lo cultural como un problema político. Como señala Hernán Valdés, editor de la revista y miembro de los Talleres de Escritores,

El fin de toda política cultural genuina debe ser de alcanzar nuestra madurez racional. La transformación de nuestra sociedad debe darse en términos de una comprensión de nuestro quehacer que haga posible el proceso y recoja su experiencia. De otro modo, incluso el intento mismo de transformación de nuestra estructura económica resultará viciado" (1971:258)

Si bien es cierto que otros centros de investigación social como el Centro de Estudios Socio-Económicos de la Universidad de Chile (CESO) y la Facultad Latinoamericana de Ciencias Sociales (FLACSO) estudiaban los problemas de la cultura como un área de especialización entre otras, el CEREN consideraba que esta era una variable de análisis transversal para la continuidad o subversión del orden social. De hecho, la dicotomía y subordinación entre infraestructura y superestructura que planteaba la izquierda tradicional, era considerada un problema que impedía entender el fracaso de las políticas para salir de la pobreza. La solución material-productiva no bastaba para lograr revertir el subdesarrollo; era necesario incluir en los análisis la transformación de los valores y las visiones del mundo. Desde un prisma económico, por ejemplo, el intelectual alemán Franz Hinkelammert hizo ver que los problemas que generaban las interpretaciones centradas solo en la circulación de las mercancías -como insistía su colega Günder Frank, académico del CESO- limitaban la comprensión de la estructura económica, ya que impedían entender por qué las políticas de desarrollo fracasaban. Para el equipo de la institución católica, era evidente que para alcanzar el socialismo había que generar un proyecto superador del desarrollismo capitalista que incluyera el conjunto de valores y conductas sociales que las estructuras reproducían (Fernández, David, 2012:119).

Nuestro trabajo postula que el desarrollo de las fuerzas productivas compromete el desarrollo de una totalidad, ya que este no puede ser reducido al mero economicismo ; el proyecto socialista que hemos desarrollado en América Latina, por lo tanto, no es una "solución economicista" que disimula sus postulados políticos. El proyecto socialista es, para nosotros, el producto de una concepción global, que no se basa exclusivamente en las necesidades de redistribuir el ingreso, de ampliar la acumulación del capital y de abrir en el exterior los mercados que estaban cerrados hasta el momento. Es más que eso lo que pensamos: al afirmar que el socialismo es la superación del subdesarrollo, y esto implica tanto el cambio de las características capitalistas y de los efectos dependientes de sus estructuras, como del conjunto de valores y actitudes sociales que dichas estructuras reproducen (Cuadernos de la Realidad Nacional, 1970:12)

Desde este prisma, el centro identificó tres áreas-problemas que permitían acercarse a las tendencias de la sociedad chilena: la relación entre la cultura, el subde- 
sarrollo y la dependencia; la relación entre la cultura y subculturas, y por último, el rol de la ciencia y la tecnología en una situación de subdesarrollo. Estos campos de investigación se irán delimitando en función de los requerimientos de la contingencia nacional y del compromiso político que asumen con el gobierno de Salvador Allende.

El triunfo de la Unidad Popular marcó una nueva etapa para el Centro y la Universidad. Bajo la dirección del sociólogo Manuel Garretón (1971-1973), el CEREN asumió públicamente una práctica intelectual comprometida; es decir, "un trabajo académico en contacto directo con los actores que encarnan un proceso de cambio social y que forme parte integrante de ese proceso" (Garretón 1971 7). Si bien es cierto que este manifiesto significó un cuestionamiento a aquellos académicos que insistían en definir su labor de intelectual desde el discurso de la "conciencia crítica", cabe constatar que la vinculación del CEREN con los actores sociales encargados del proceso político, "el pueblo", no alcanzó a institucionalizarse. Como recuerda Jorge Larraín, "el contacto con los actores sociales fue mínimo, ya que los insumos [de análisis] provenían en su mayoría de registros ya establecidos por distintas organizaciones" (Jorge Larraín entrevista personal, 4 noviembre del 2014). Salvo algunas excepciones, como por ejemplo los trabajos realizados con determinadas organizaciones sociales y políticas por el equipo de Armand Mattelart, la regla general fue la continuidad de las prácticas cientificistas, paradójicamente criticadas por los mismos investigadores, en donde prima la observación vertical sobre el "sujeto-objeto" de estudio. Por lo mismo, no es extraño el asombro que en ciertos sectores del Centro causó la articulación de distintos tipos de organizaciones de base, con el objetivo de crear sus propias tácticas y estrategias políticas revolucionarias sin la mediación de un agente intelectual. Como señala el matrimonio Mattelart en la entrevista con el comunicólogo Mario Kaplún:

Desde la perspectiva de la comunicación, el proceso chileno se podría dividir en dos períodos: en el primero, son los intelectuales y los dirigentes políticos los que marcan las pautas, los que -explícita o implícitamente- formulan y orientan la política comunicacional; pero, a partir de octubre de 1972, cuando la reacción se moviliza y se desencadena la gran huelga de los dueños de camiones y de los gremios patronales, comienza a gestarse un nuevo período. Surgen otros actores paralelos, que proponen un nuevo tipo de organización y un nuevo tipo de comunicación. Eso nos impactó muchísimo, nos llevó a revisar todos nuestros esquemas". (Kaplún, 1988: 4)

Asimismo, varios de los académicos de planta asumieron cargos estratégicos en el Gobierno de la Unidad Popular, desvinculándose profesionalmente del Centro. ${ }^{10}$ Solo algunos de ellos como, por ejemplo, Armand y Michéle Mattelart, Mabel Piccini y Tomás Moulián mantuvieron la filiación académica. La relación estrecha que se dio entre gobierno y universidad permitió sobrepasar los límites partidistas en el desarrollo de políticas públicas, y generó las condiciones para que los intelectuales "expertos" presentaran y ejecutaran propuestas disímiles a las realizadas por los partidos de la UP, manteniendo una lealtad política con el gobierno, como fue el caso del equipo dirigido por Armand Mattelart (volveremos sobre esto más adelante). 
A pesar de las presiones y las divisiones internas que experimentaba el grupo reformista al interior de la Universidad Católica con el triunfo de Allende, la continuidad de Fernando Castillo como rector permitió que el proyecto académico se sobrepusiera a las luchas internas. Para el arquitecto Castillo, la consolidación de la Reforma era clave para aportar en los proyectos de transformación que se auguraban: "el papel de la Universidad en esta hora -señalaba al diario El Mercurio-- es pues importante y su responsabilidad aun mayor, debe llevar adelante su reforma con el fin de participar activamente en la construcción de una nueva sociedad" (Castillo, 1970).

El apoyo abierto de Rectoría al nuevo gobierno significó, la continuidad y consolidación de aquellas unidades consideradas los pilares de la reforma pero reconocidas públicamente como "marxistas", como fue el caso del CEREN y, además, el fin de la asociación política entre demócratas cristianos y militantes de izquierda que habían dado origen al interior de la universidad al Partido Reformista. ${ }^{11}$ De esta manera, la unidad académica dispuso de recursos para desarrollar las áreas de investigación. Esto significó ampliar la planta para constituir equipos de trabajo dedicados a pensar la transformación socialista de manera global (Tabla 1).

En torno a las investigaciones se constituyeron distintos tipos de instancias, las cuales se dividieron en cursos generales, seminarios básicos y superiores. Los primeros se diseñaron en función de los temas de contingencia nacional, cuyo fin era proporcionar los contenidos mínimos de inmersión político-cultural que permitieran generar una plataforma de reflexión y debate crítico en la comunidad universitaria (estudiantes, docentes y administrativos). Los seminarios básicos eran cursos disponibles para todas las carreras, mientras que los calificados como superiores buscaban orientar en el desarrollo de habilidades investigadoras. Los cursos que se impartieron durante el año académico y el verano también dispusieron de vacantes para distintos actores sociales que no estaban ligados a la universidad. La puesta en marcha de la planificación académica significó que, entre 1969 y 1971, el alumnado regular creciera en un $173,5 \%$, ya que de 200 estudiantes se pasó a 547.

Desde 1970 a 1973, la plantilla -compuesta por profesores con jornada y asociados- aumentó en un 338\%, de ocho a veintisiete profesores (Programas docentes, 1970-1973). El aumento progresivo de docentes no tan solo pretendió cubrir las necesidades requeridas por la demanda de servicio, sino también buscó reforzar el criterio de interdisciplinariedad del centro, esto es, la de un espacio de trabajo sistemático compuesto por equipos con especialistas de distintas áreas del conocimiento, capaces de sintetizar sus experticias y plasmarlas en una metodología (Garretón, 1971). Sin embargo, se puede constatar una marcada presencia de sociólogos y abogados (54\% de la plantilla), poniendo en cuestionamiento el carácter interdisciplinario de los equipos de investigación.

El segundo objetivo del centro lo constituyeron las estrategias de vinculación con el medio. Las reflexiones -dirigidas por los extranjeros que llegaron a la universidadconcluyeron que el ejercicio docente y la formación profesional tenían que estar en función de las necesidades de la sociedad, incluyéndose a esta en los procesos de 
construcción de saber. Esta mirada venía a subvertir las prácticas tradicionales de la academia --que se basaban en la imposición unidireccional del conocimiento--, avalando el intercambio integral entre distintos agentes académicos y sociales desde una relación horizontal. Tanto el directorio del Centro como la Universidad sabían que era todo un desafío llegar a aquellos sectores que no tenían acceso alguno a la producción universitaria. Para ello se diseñaron distintas líneas de acción que estuvieron a cargo de la Comisión de Difusión Científica, la cual trabajó en conjunto con la Vicerrectoría de Comunicaciones.

Tabla 1. Organigrama del Centro de Estudio de la Realidad por áreas de investigación, 1970-1973

\begin{tabular}{|c|c|c|}
\hline \multicolumn{3}{|c|}{ CENTRO DE ESTUDIOS DE LA REALIDAD NACIONAL, 1970 - 1973} \\
\hline Áreas de Estudio & Subáreas de Estudios & Equipo Responsable \\
\hline \multirow{3}{*}{$\begin{array}{l}\text { Económica } \\
\text { Tecnológica }\end{array}$} & Económico-Tecnológica & \multirow{3}{*}{$\begin{array}{l}\text { Franz Hinkelammert, } \\
\text { Manuel A. Garretón, Pilar } \\
\text { Vergara, Kalki Glausser }\end{array}$} \\
\hline & Valores vigentes y posibilidad de desarrollo & \\
\hline & Estructura de clase y movimiento obrero & \\
\hline \multirow{3}{*}{$\begin{array}{l}\text { Político } \\
\text { institucional }\end{array}$} & Estudio de partido de clase & \multirow{3}{*}{$\begin{array}{l}\text { Tomas Moulián, Aníbal } \\
\text { Barreto, Norbert Lechner, } \\
\text { Hernán Villablanca, } \\
\text { Patricio Biedma }\end{array}$} \\
\hline & Clase y coyuntura política & \\
\hline & Legalidad e institucionalidad & \\
\hline \multirow{4}{*}{ Cultura-Ideología } & $\begin{array}{l}\text { Comunicación masiva, cultura y } \\
\text { Revolución Socialista }\end{array}$ & \multirow{4}{*}{$\begin{array}{l}\text { Armand Mattelart, } \\
\text { Michèle Mattelart, } \\
\text { Mabel Piccini, Rafael } \\
\text { Echeverría, Fernando } \\
\text { Castillo, Jorge Larraín, } \\
\text { Antonio Avaria }\end{array}$} \\
\hline & $\begin{array}{l}\text { Problemáticas de la televisión chilena en el } \\
\text { proceso chileno }\end{array}$ & \\
\hline & Cultura proletaria y conciencia de clase & \\
\hline & $\begin{array}{l}\text { Interpretación social de Chile a través de la } \\
\text { Literatura }\end{array}$ & \\
\hline
\end{tabular}

Fuente: Investigaciones y otras actividades del CEREN, Cuadernos de la Realidad Nacional, $\mathrm{N}^{\circ} 9$ (Sep. de 1971), Universidad Católica, Santiago, pp. 258 -264.

Primero, se realizó un proyecto educativo en conjunto con Canal 13 UCTV, que se sustentó en propuestas -previas incluso al nacimiento del centro- basadas en la metodología de alfabetización elaborada por Paulo Freire. Por otra parte, también se planificó crear en conjunto con el Instituto Fílmico de la casa de estudio, una serie de películas que abordaran los temas nacionales de manera que esta información pudiera circular por la señal televisiva y por las distintas salas de cine a lo largo del país. Asimismo, se realizaron, en conjunto con la Federación de Estudiantes, distintas actividades comunitarias sobre la realidad nacional y promoción popular. Sin embargo, 
será una revista la que logrará mayor aceptación y circulación en el espacio académico local y regional.

La revista Cuadernos de la Realidad Nacional apareció en septiembre de 1969, con la finalidad de ser "tribuna para todas aquellas personas de dentro o fuera de la comunidad universitaria que hagan aportes valiosos e interesantes desde el punto de vista del conocimiento general, del análisis global o de aspectos significativos de nuestra sociedad: de su pasado, de su presente y de sus perspectivas futuras" (Cuadernos de la Realidad Nacional, 1969: 1). Con este propósito en la mira, se acordó publicar tres números al año más un suplemento especial dedicado a los Seminarios de Investigación.

Pese a la intención de plantearse como una revista académica abierta e inclusiva con la sociedad, tanto su formato como su contenido se ajustaron a los cánones tradicionales vale decir de divulgación teórica-ideológica. Los temas estaban en plena relación con las áreas problemas que se había definido desde sus inicios y en sus índices solo figuraban académicos y políticos de elite.

Es más, en los 16 números que circularon entre 1969 y 1973, el 85\% de los artículos estaban vinculados a distintos espacios académicos relacionados con las Ciencias Sociales. De hecho, el $57 \%$ de los autores que publicaron en los Cuadernos entre 1969-1972 ejercían como docentes de la unidad académica (Tabla 2). ${ }^{12}$ Si bien el $43 \%$ restante provenía de distintos espacios académicos, existía un predominio de expertos del CESO de la Universidad de Chile. Lo que no es extraño si consideramos que desde sus inicios ambos centros asumieron un papel protagónico en las reflexiones sobre los cambios sociales. Entre 1969 y 1972, de hecho, el CEREN concentró la mayor cantidad de publicaciones por años, de las cuales el $80 \%$ se agotó. Así, la revista difundió un campo de significación marcado por un horizonte revolucionario, que lo distinguió del resto de los discursos académicos y políticos dentro de la Universidad y de la izquierda. Al mismo tiempo, la revista constituyó un espacio de intercambio intelectual, pero incapaz de generar las condiciones de participación de otros actores sociales.

A la revista se suman otras publicaciones como la Colección Documentos de Trabajo y los Libros CEREN-CESO. Toda la producción de bienes académicos fue gestionada por el Centro y la Vicerrectoría de Comunicaciones. Se nombró al escritor Hernán Valdés como Secretario de Redacción de la revista y Jefe de Publicaciones de la unidad. 
Tabla 2. Participación de docentes del CEREN en los Cuadernos de la Realidad Nacional, 1970 -1972

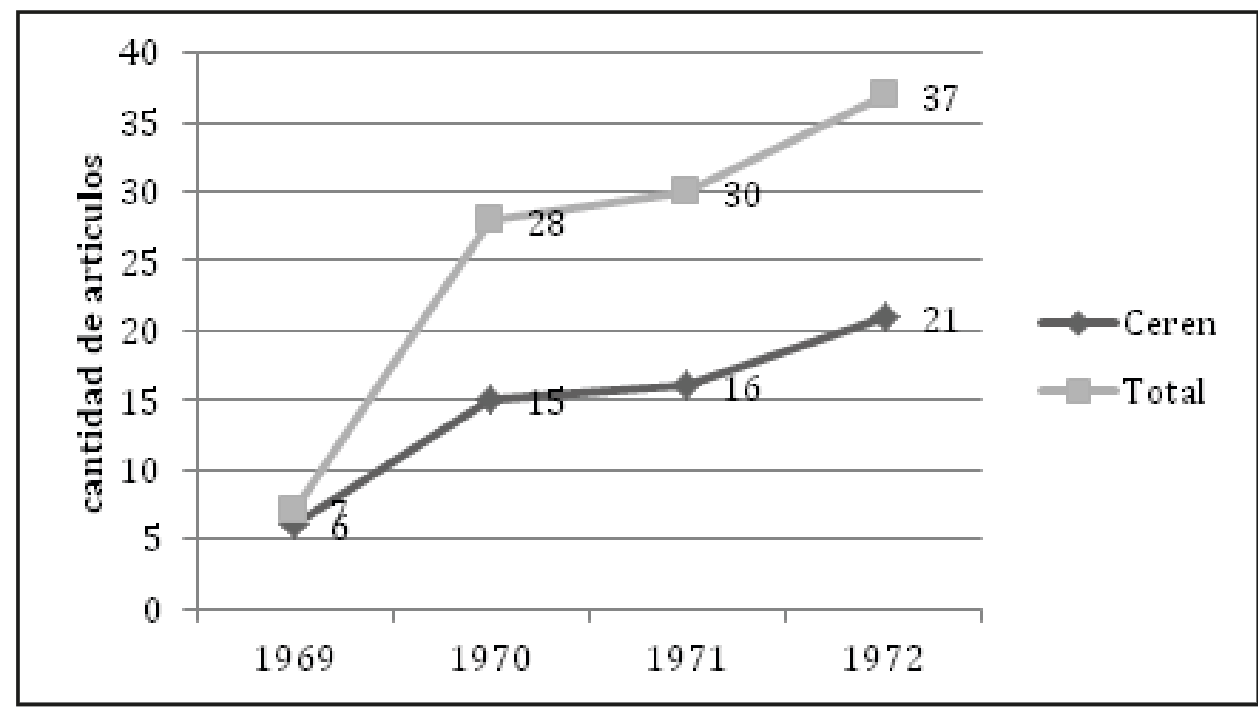

Fuente: Elaboración personal a partir de la información obtenida en los Cuadernos de la Realidad Nacional,1969, 1970, 1971, 1972.

Por último, el Centro se propuso constituir redes con las instituciones y los sectores encargados de llevar a cabo el proceso político de transformación, con el propósito de desarrollar el vínculo entre la teoría y la praxis social. Para el centro, las relaciones con el mundo externo a la universidad no podían reducirse a un simple criterio de extensión, pues ellos no realizaban "trabajos por encargo". Más bien se propuso una práctica docente de colaboración activa y dialógica, en la medida que era la única forma de construir un proyecto histórico. Consideraban necesario redefinir el trabajo académico tradicional en función del contexto en que se desenvolvía; es decir, una relación dialéctica entre el saber y el hacer en función del proyecto histórico.

A través de estas medidas, el CEREN abrió la Universidad a la realidad nacional, subvirtiendo - de una manera matizada- el sentido académico tradicional.

\section{Pensar las Comunicaciones Revolucionarias. Tensiones y ruptura entre la experticia académica y las directrices políticas.}

Desde su fundación en 1968, el CEREN manifestó un explícito interés por el estudio de las comunicaciones, pues consideraba que eran claves en la lucha contra "la enajenación y dependencia cultural" (Objetivo y Programa, 1968). Tanto la cultura como la ideología eran consideradas campos estratégicos en las transformaciones 
de los sentidos de mundo. A principios de los años sesenta, de hecho, los medios de comunicación de masas se vuelven relevantes para el mundo académico ya que eran considerados - principalmente por la sociología norteamericana- instrumentos clave en la transformación de las mentalidades subdesarrolladas del continente (Varela 2010, Rivera, 2014). Frente al dominio de las teorías funcionalistas comenzaron a surgir miradas críticas que cuestionaron la tradicional interpretación de la lucha ideológica de la época; esto es, de aquellas posturas que sostienen, por una parte, la capacidad de los medios como instrumentos de sometimiento y naturalización de las ideas y valores, y, por otra, la existencia de un receptor pasivo. En este contexto, el Centro de Estudios de la Realidad llegó a ser referente en el espacio local y regional, con las investigaciones a cargo del demógrafo Armand Mattelart, y las licenciadas en letras Michèle Mattelart y Mabel Piccini.

En 1962, Armand Mattelart se incorporó al Instituto de Sociología de la Universidad Católica, como resultado de una serie de políticas de internacionalización que buscaban establecer redes con el resto de las instituciones pontificias que abordaran los temas sobre población y planificación familiar (Beigel, 2011, Mattelart, 2014). Su condición de especialista en demografía generó las condiciones para que desempeñara, de manera paralela, puestos en distintos espacios relacionados con el análisis de los fenómenos sociales como el Centro para el Desarrollo y Social de América Latina (DESAL, 1962-1964), la Comisión Pontificia de Planificación Familiar (1965-1968) y el Instituto de Capacitación e Investigación en Reforma Agraria (ICIRA, 19671968), en el cual participó como director del Departamento de Desarrollo Social. Su paso por esta última institución permitió una diversidad de contactos internacionales, que abrieron el campo de reflexión de Armand y Michèle Mattelart. Como recuerda Armand en su entrevista con Sénécal

...era la primera vez que trabajaba de manera continúa, con un equipo internacional sobre la realidad chilena [...] Estos frecuentes contactos con el campesinado, y el trabajo cotidiano con investigadores motivados por una aproximación cristiana a las injusticias y a las desigualdades sociales, constituyen factores fundamentales en la maduración de mi conciencia social. No diría conciencia política, propiamente dicha. No, y me hizo falta mucho tiempo. Me refiero a esa conciencia social que nos prepara para ese momento en que uno debe hacer suyo un proyecto de cambio colectivo (2014: 95).

De esta manera, las múltiples redes que se fueron entretejiendo desde su llegada a Chile fueron claves en la evolución desde su área de interés original, es decir, de la socio-demografía al estudio de las comunicaciones. La crítica a los paradigmas difusionistas norteamericanos les llevó a indagar sobre aquello que era omitido por esta escuela: el entorno socio-cultural que rodea a los sujetos. Desde el prisma de la etnografía social, el matrimonio Mattelart comenzó un estudio exploratorio sobre la reacción de las mujeres populares en un contexto de cambio social a partir de los usos que ellas daban a los medios de comunicación. ${ }^{13}$ La publicación fue el inicio de una serie de investigaciones que se destacaron por el uso de metodologías novedosas para el campo académico nacional y, específicamente, por la aplicación del análisis del discurso realizado por los lingüistas estructuralistas. ${ }^{14}$ 
Así, con el estallido del conflicto de la Reforma de la Universidad Católica, el matrimonio centró su atención en la virulencia de los mensajes emitidos por la prensa nacional. No era la primera vez que constataban la agresividad de los medios de comunicación adscritos a los sectores tradicionales del país frente a reformas que ponían en cuestionamiento el orden de clase establecido y el impacto que esto tenía en la población (Mattelart, Castillo, Castillo, 1970). ${ }^{15}$ Por lo mismo, una vez constituido el CEREN, no se dudó en establecer un área de estudio sobre las comunicaciones y la cultura con Michèle Mattelart y Mabel Piccini. ${ }^{16}$

En 1967, y en la misma línea que en el ICIRA, el equipo comenzó a investigar sobre el impacto de los mensajes que difundían los medios de comunicación en la sociedad. Los resultados se publicaron en un especial de la revista Cuadernos de la Realidad Nacional en marzo de 1970 con el título de "Los Medios de Comunicación de Masas. La ideología de la prensa liberal en Chile". Desde los estudios de lingüistas europeos (Greimas, Barthes y Kristeva) y en sintonía con el especialista en semiótica, el argentino Eliseo Verón, el equipo se propuso desvelar el carácter alienante de las comunicaciones y, asimismo, denunciar el alto grado de concentración y dependencia económica de los medios. El impacto de la publicación fue inmediato. El escenario de elecciones presidenciales determinó la recepción del texto, exponiendo las tensiones sociales y políticas del período. Distintos sectores políticos -tanto de izquierda como de derecha-manifestaron su apoyo o repudio a la interpretación del equipo de la Católica. Si para los sectores conservadores esto fue considerado como "marxismo ficción" (Martínez, 1970), para los sectores de izquierda sirvió de plataforma desde donde justificar las críticas y denuncias sobre las malas prácticas que realizaban las empresas de la comunicación al seleccionar y difundir información (Zarowsky, 2013).

El descontento del gremio y de los pequeños empresarios de los medios de comunicación era evidente. Desde la aprobación de la llamada Ley Mordaza (No. 15476) por el gobierno de Jorge Alessandri, el Colegio de Periodistas empezó a manifestar su malestar sobre los límites que establecía la normativa para acceder a información y publicarla. La Asociación de Periodistas y Trabajadores de las Comunicaciones, crearon una Comisión de Defensa de la Libertad de Expresión con el propósito de velar por el "buen" funcionamiento de los derechos constitucionales de informar (Punto Final, 1968). Pese a los esfuerzos realizados con las autoridades políticas respectivas, que se tradujeron en falsas promesas de los candidatos presidenciales -sobre todo en fechas de elecciones- para su derogación, la ley siguió vigente hasta el triunfo de Salvador Allende (Actas del Consejo Nacional del Colegio de Periodistas, 19641970).

En síntesis, el descontento y la radicalización política del periodo condicionaron el "éxito de ventas" del número del CEREN. Si bien el objetivo de la investigación tenía por finalidad identificar las maneras en que los sectores dominantes instalaban su verdad e intereses como universales a través de la decodificación de los mensajes, la lectura sesgada del texto no impidió el éxito de la edición, instalando al equipo del CEREN -y asimismo a la Universidad Católica- como una institución crítica, comprometida con el quehacer nacional, y pionera en el estudio de las comunicacio- 
nes. ${ }^{17}$ En efecto, la mayoría de los académicos no solo se adscribieron al proyecto político, sino que también manifestaron un interés particular por ciertos partidos como el Movimiento de Acción Popular Unitaria (MAPU) y el Movimiento de Izquierda Revolucionario (MIR). ${ }^{18}$

Como "especialistas de izquierda" de un campo de estudio nuevo y relevante en el marco de las luchas ideológicas, el equipo compuesto por Armand y Michèle Mattelart y Mabel Piccini asumió funciones en el gobierno sin dejar sus labores en el Centro, como responsables del área problema de "Cultura e Ideología" (Tabla 1). ${ }^{19}$ Sin embargo, la falta de solidez del Frente Cultural de la UP obstaculizó la recepción de la propuesta comunicacional que desarrollaron. El vínculo con la institución académica permitió sostener un grado de autonomía para definir posiciones y las fronteras dentro del espacio más amplio del campo intelectual, transgrediendo las directrices de los partidos políticos sin ser considerados desleales. Sin embargo, las tensiones entre las prácticas científicas y las políticas se hicieron sentir de inmediato.

Antes de la ratificación parlamentaria en las elecciones del setenta, el matrimonio Mattelart y Piccini ya había comenzado a reflexionar sobre el tipo de cultura y comunicaciones que necesitaba un país en proceso de transición al socialismo. El problema no era nada fácil pues su discusión implicaba cuestionar los contenidos de la Vía Chilena, es decir, revisar críticamente tanto la propuesta política como la recepción de ésta por el pueblo, para poder así consensuar un proyecto a construir, en un contexto que exigía unir voluntades y evitar discrepancias. Así como todos los intelectuales de izquierda estaban de acuerdo en que había que erigir una "Nueva Cultura" capaz de transformar las visiones hegemónicas del mundo que impedían la liberación del pueblo, también eran evidentes las disputas internas donde se cruzaban los intereses personales con los partidistas y con la falta de una metodología.

Para el equipo del CEREN, el mayor problema lo constituía la continuidad del modelo democrático liberal (Mattelart,1971:54). La firma de las garantías constitucionales impedía, por una parte, transformar el sistema de comunicación según las necesidades del momento y, a su vez, coartaba el desarrollo de líneas de acción comunicacionales enfocadas a comprender la importancia de la relación entre la práctica revolucionaria y la búsqueda de una nueva cotidianeidad, por lo que se hacía más necesario desmitificar la realidad. Así lo dejó entrever Armand Mattelart en su conferencia en el seminario organizado por la Asociación de Periodistas de Izquierda en abril de 1971, donde llamó al gremio a desvelar los instrumentos de ideologización para crear una racionalidad distinta, capaz de disputar el campo simbólico y así devolverle el habla al pueblo (Punto Final, 1971).

La estrategia que proponía subvertía la matriz comunicativa dominante pues incluía al receptor en la construcción del mensaje; es decir, de manera activa. No bastaba con estudiar los efectos de la recepción sino que había que incluir a las masas en los procesos de producción. Para ello se crearon talleres populares de lectura que operaron en distintas organizaciones sociales. Como bien señala Mariano Zarowsky, "los talleres populares permitían quebrar la unidireccionalidad y el carácter cerrado 
de los mensajes, de modo que lanzado por su emisor a las masas retornaría a su emisor, desalienado y enriquecido" (2009: 5). De este modo se pretendía que los sujetos se transformaran en los autores de sus propias vidas.

La propuesta del equipo del CEREN no fue recepcionada con el mismo entusiasmo por todos los sectores de la izquierda, principalmente el Partido Comunista (PC), con quien compartía espacio en Quimantú. En el Documento de la Asamblea Nacional de Trabajadores de la Cultura como en los Cuadernos de la Realidad Nacional, Carlos Maldonado -Director del Instituto de Investigación Marxista y Encargado Nacional de Cultura del partido- cuestionó duramente el "voluntarismo" al cual aludían los académicos para construir la Nueva Cultura (1971:75). Para el PC, el mundo de la conciencia no podía reducirse a un acto de autonomía, ya que impediría alcanzar los objetivos revolucionarios. La diversidad cultural de lectores exigía levantar de un modo planificado una política cultural que contemple estas diferencias, a cargo de cuadros culturales; esto es, sujetos con una formación integral en donde se funde la experticia técnica con la política. Así lo deja entrever el intelectual comunista Volodia Teitelboim “... no entendemos la tarea de estos cuadros simplemente como asesores artísticos u organizadores de espectáculo, sino además como orientadores políticos e ideológicos" (1971:12). De esta manera, en esta etapa de la transición el PC consideraba que los intelectuales eran los encargados de educar a través de los mensajes a las masas, con el propósito de que alcanzaran un nuevo nivel de conciencia y organización. Desde este prisma, los medios de comunicación de masas eran considerados instrumentos relevantes para el éxito de este proceso: "instrumento de liberación del pueblo y del hombre en el sentido de darle conciencia exacta, cultura auténtica, los mejores productos del espíritu" (1971:52), pues irrumpían diariamente en la cotidianeidad de los sujetos, y su efectividad radicaba en la simpleza y cercanía del lenguaje. Por lo tanto, insistir en la vía argumental como táctica transformadora era impensable. Como dice Maldonado,

Nada sacamos destruyendo valores -por falsos que éstos sean- mediante la vía argumental, dentro de un modo fantástico donde para el lector común la lógica y la simbología social no cuentan. La lectura "inteligente" que realizan los teóricos de la seudo cultura comercial, teniendo un fin analítico de indiscutible valor, no resulta inteligente trasladarla mecánicamente a los vehículos de difusión. Es preciso, por el contrario, ser capaces de "traducirla" a un lenguaje práctico, a imágenes sencillas ligadas a la realidad de su propio "mundo". Es decir, seguir trabajando, como lo ha sabido hacer la burguesía, dentro de la gama de "valores imaginativos" (fantasía infantil y juvenil, por ejemplo); pero ahora con un nuevo contenido desalienante" (Cuadernos de la Realidad Nacional, 1972:79)

Claramente esta mirada difería de la postura de Mattelart y su equipo, quienes consideraban a los medios de comunicación de masas como una institución social que (re) significa permanentemente el campo simbólico en función de los intereses de la estructura dominante. La efectividad receptiva de este racionamiento radicaba en las estrategias discursivas "inclusivas" que circulaban en sus mensajes. Por lo mismo era urgente desmitificar el discurso de la neutralidad con que se revestían los medios y proveer recursos para promover la recepción crítica en los sectores populares. 
La marcha del proceso fue evidenciando las contradicciones y los límites en los que se desenvolvía la práctica comunicativa. No era posible, decían los académicos, reducir la lucha a la producción de mensajes sin cuestionarse las condiciones materiales de recepción de los sujetos. Los resultados de la encuesta de la Oficina Gubernamental de Informaciones y Radiofusiones (OIR) fueron categóricos al señalar que la prensa de izquierda generaba poco interés en los lectores. La organización declaró que de los tres millones de chilenos que habitualmente leían periódicos, estos dividían sus preferencias entre cinco diarios de izquierda y seis de oposición. Todas estas publicaciones vendían un total de 853 mil ejemplares, cada uno leído por 3 o 4 personas, de los cuales solo uno se informaba a través de la prensa de izquierda (Chile Hoy, 1972). A esto se sumó la irrupción de una prensa popular desarrollada en el seno de los cordones industriales, órganos de democracia directa, que llamó la atención de los investigadores. Esta iniciativa legitimó la premisa que para crear una nueva cultura no sólo se necesita transformar la visión de mundo, sino también su modo de organizarla considerando la participación de los diversos actores sociales. Cada cordón contaba con un órgano de comunicación dirigido por los mismos obreros o por periodistas militantes que empezaron a formar "corresponsales obreros". (Mattelart, 1974: 77-123). Asimismo, Michèle Mattelart y Mabel Piccini comenzaron a reflexionar sobre la recepción de los medios en los sectores populares (Mattelart et. al., 1974) Estos trabajos señalaron la importancia del contexto en el cual está inserto el receptor. Para el equipo, la clase no es determinante en las lecturas que se llevan a cabo, sino que era necesario considerar los contextos individuales, biográficos y sicológicos de los lectores para entender la decodificación que los sujetos realizan. De esta manera, y como señala Zarowsky

En el fondo, para los autores las diferencias en materia de política cultural expresaban las divergencias respecto a la estrategia política que en ese momento atravesaban la izquierda chilena, entre los partidos de la vía democrática, por un lado, y los partidarios de la estrategia insurreccional y de construcción de poder popular a la que se acercaban más los Mattelart, por otro" (2007: 12)

\section{Conclusión}

En síntesis, el proyecto modernizador que se inició durante la década de los cincuenta, sentó las bases para la llegada de una diversidad de intelectuales europeos y latinoamericanos, que dinamizaron el intercambio y la producción de nuevos conocimientos. La Pontificia Universidad Católica de Chile incorporó a sus equipos docentes, académicos europeos, brasileños y argentinos vinculados a los sectores mas progresistas de la Iglesia Católica, quienes comenzaron a reflexionar la transformación social desde la cultura y las comunicaciones. La influencia de los brasileros católicos exiliados como Paulo Freire y Ernani Maria Fiori entre otros, fue clave para el desarrollo de la cultura y las comunicaciones, ya que se constituyeron como un lugar teórico-metodológico desde donde reflexionar. El modelo de análisis no solo se 
aplicó en los centros de investigación como ICIRA sino que también sirvió de plataforma para re-diseñar al centro universitario católico en función de lo social. Es decir, como un espacio de comunicación dialógica entre los académicos, los estudiantes, los administrativos y la sociedad. En el nuevo organigrama, los centros académicos como el Centro de Estudios de la Realidad Nacional se instalaron con la entidad articuladora entre la universidad y la sociedad, entre lo cultural y sub-cultural.

Así, el CEREN marcó un punto de inflexión en el escenario académico local. Por una parte, instaló a la cultura -en su más amplio sentido- como un articulador protagónico para el desarrollo de los pueblos, y, por otro lado, abrió un nuevo campo de estudios: el de las comunicaciones, área de trabajo a cargo de Armand y Michèle Mattelart y Mabel Piccini. Desde 1968 a 1973, el equipo fue avanzando en sus estudios en función del contexto. Así, de la denuncia sobre la dominación ideológica de las empresas periodísticas pasaron a la reflexión sobre la construcción de una cultura revolucionaria basada en las prácticas populares, que no alcanzó a legitimarse ni a masificarse al interior de la izquierda. La falta de claridad de una política cultural proveniente desde el gobierno, y la fragmentación del Frente Cultural de la Unidad Popular, terminaron por aislar y reducir las iniciativas del equipo a un ejercicio experimental que finalizó -al decir de algunos- con la irrupción del golpe del 73. Sin embargo, los vínculos que se construyeron desde el mundo académico y político nutrió a una generación que será fundamental para el desarrollo de las comunicaciones alternativas durante la dictadura.

\section{Referencias bibliográficas}

Actas del Consejo Nacional del Colegio de Periodismo, 1964 -1970.

Objetivos y Programa de Trabajo del Centro de Estudios de la Realidad Nacional (Mimeo), 25 de abril 1968.

Partido Demócrata Cristiano. Documentos de la Primera Convención Nacional: Resolución sobre política nacional, objetivos del partido. Santiago: Editorial del Pacífico, 1960.

Universidad Católica de Chile. Vicerrectoría Académica. Dirección de Estudios: Los Departamentos y el proceso de Departamentalización (Mimeo), 30 de julio de 1970.

Bibliografía

BECCA, Carlos E., RICHARDS, Cecilia, y BIANCHETTI, Lucidio. "Ernani Maria Fiori: un profesor brasilero en tierras chilenas-testimonios". Educação \& Realidade, Porto Alegre, No. 3, Vol. 38 (jul. -sept., 2013): 1021 -1034. Web. 15 enero 2015.

BEIGEL, Fernanda (Dir.). Autonomía y dependencia académica. Universidad e investigación científica en un circuito periférico: Chile y Argentina (1950-1980) Argentina: Editorial Biblos, 2010. 
BEIGEL, Fernanda. Misión Santiago. El mundo académico jesuita y los inicios de cooperación internacional católica. Santiago: LOM Ediciones, 2011.

BERNEDO, Patricio, y PORATH, Williams. "A tres décadas del Golpe: cómo contribuyó la prensa al quiebre de la democracia chilena" Cuadernos de Comunicación, No. 16 - 17 (2003-2004): 114 -124.

BOWEN S., MARTÍN. "Construyendo nuevas patrias. El proyecto sociocultural de la izquierda chilena durante la Unidad Popular" Seminario Simon Collier 2006. Santiago: LOM Ediciones, 2006.

BRUNNER, José J., y FLISFISCH, Angel. Los intelectuales y las instituciones de la cultura. Santiago: FLACSO, 1983.

BRUNNER, José J., y CATALÁN, Gonzalo. Cinco estudios sobre cultura y sociedad. Santiago: FLACSO, 1985.

BRUNNER, José J. Un espejo trizado: ensayos sobre cultura y política culturales. Santiago: FLACSO, 1988.

CASTILLO V., Fernando. "La Universidad Católica de Chile y el momento actual" El diario El Mercurio (22 de septiembre de 1970)

CHONCHOL, Jacques. "¿Qué es el CEREN? Cuadernos de la Realidad Nacional, No. 1 (Sep. 1969): 5 -14.

DEL VALLE, Carlos. "Políticas de Comunicación y cultura, participación y estructura de los medios en Chile" en Légete. Estudios de comunicación y sociedad, No. 5 (2005): 115-137. Web.

DOONER, Patricio, y LAVADOS, Iván. La Universidad Latinoamericana: visión de una década. Santiago: CPU, 1979.

DOONER, Patricio. Periodismo y Político: la prensa de izquierda en Chile, 19701973. Santiago: ICHEH, 1985.

FERMANDOIS, Joaquín. La Revolución inconclusa. La izquierda chilena y el gobierno de la Unidad Popular. Santiago: CEP, 2013.

FERNÁNDEZ L., Marcos. "Nuestra forma de alienación es simultáneamente nuestra única forma de expresión. Debate intelectual, política cultural y compromiso político en la intelectualidad de izquierda en Chile, 1970 -1973" En 1973. La vida cotidiana de un año crucial. Santiago: Planeta, 2003.

FERNÁNDEZ N, Estela, y DAVID S., Gustavo. Teología Profana y Pensamiento Crítico. Conversaciones con Franz Hinkelammert. Buenos Aires: CLACSO, 2012.

GARRETÓN, Manuel. "Investigaciones y otras actividades del CEREN". Cuadernos de la Realidad Nacional, No. 9 (Sep. de 1971):258 - 264.

GARRETÓN, Manuel. Ciencias Sociales en Chile. Santiago: Academia de Humanismo Cristiano, 1982.

GARRETÓN, Manuel, y MARTÍNEZ, Javier (Dir.) La Reforma en la Universidad Católica de Chile. Santiago: Ediciones SUR, 1987.

GUTIÉRREZ, Paulina, MUNIZAGA, Giselle, y RIQUELME, Alfredo. Sistema de Comunicación en Chile: proposiciones interpretativas y perspectivas democráticas. Santiago: CENECA, 1985. 
HINKELAMMERT, Franz. "Prólogo" Cuadernos de la Realidad Nacional, No. 6 (Dic. 1970): 11-14.

HUNEEUS, Carlos. La Reforma Universitaria: veinte años después. Santiago: CPU, 1988.

KAPLÚN, Mario. "Los Mattelart hoy: Entre la continuidad y la ruptura. Una visión desmitificadora de "Los Nuevos Paradigmas"” En Dia-Logos de la comunicación, No. 21 (julio, 1988) Web. 15 enero 2015.

KREBS, Ricardo. Cien años de historia universitaria: la Pontificia Universidad Católica de Chile 1988-1988. Santiago: Boletín de la Academia Chilena de la Historia, 1989.

LOZOYA, Ivette. "Debates y tensiones en el Chile de la Unidad Popular ¿la traición de los intelectuales? Pacarina del Sur, No. 19, Vol. 11 (abril - junio, 2014) Web. 14 de enero de 2015.

MALDONADO V., Carlos. "La Revolución Chilena y los problemas de la Cultura". La revolución chilena y los problemas de la CULTURA. Santiago: Talleres Horizonte, 1971.

MALDONADO V., Carlos. "El proceso cultural como incentivador de la praxis" Cuadernos de la Realidad Nacional, No. 12 (abril de 1972): 69-83.

MARTÍN-BARBERO, Jesús. La educación desde la comunicación. Buenos Aires: Editorial Norma, 2002.

MARTÍNEZ, Jesús Manuel. "Para entender los medios: medios de comunicación y relaciones sociales" En Cuadernos de la Realidad Nacional, No. 5 (Septiembre, 1970): 161-187.

MATTELART, Armand, CASTILLO, Carmen, y CASTILLO, Leonardo. La ideología de la dominación en una sociedad dependiente. Buenos Aires: Ediciones Signos, 1970.

MATTELART, Armand. "La prensa de izquierda y el Poder Popular" Revista Punto Final No. 128 (Martes 27 de abril de 1971): 1-45.

MATTELART, Armand. “¿Hacia una cultura de la movilización cotidiana? Cuadernos de la Realidad Nacional, No. 10 (diciembre de 1971): 49-96.

MATTELART, Armand, y MATTELART, Michèle. "Ruptura y continuidad en la comunicación: puntos para una polémica" Cuadernos de la Realidad Nacional, No. 12 (abril de 1972): 100-143.

MATTELART, Armand. "Prensa y lucha ideológica en los cordones industriales de Santiago: testimonios" Revista Comunicación y Cultura, No. 2 (1974): 77 - 106.

MATTELART, Armand. Por una mirada-mundo. Conversaciones con Michel Sénécal. Barcelona: Gedisa, 2014.

MATTELART, Michèle, y PICCINI, Mabel. "La televisión y los sectores populares" Revista Comunicación y Cultura, No. 2 (1974): 3 - 75.

MATTELART, Michèle. "Creación Popular y Resistencia al Sistema de los Medios de Comunicación. La experiencia del Chile Popular" Revista Comunicación y Cultura, No. 6, Vol. 6 (1978): 95-103. 
RIVERA, Carla. "La verdad está en los hechos: una tensión entre objetividad y oposición. Radio Cooperativa en dictadura". Revista Historia, No. 41, Vol. 1 (enero-junio 2008): 79-98.

RIVERA, Carla. Pensar las Comunicaciones en y desde la Revolución. Documento de Trabajo. Santiago: CIDOC-Finis Terrae, 2014.

SANTA CRUZ, Eduardo. Prensa y Sociedad. Santiago: Editorial Universitaria, 2014.

SCHERZ G., Luis. "Reforma y Contrarreforma en la Universidad Católica de Chile (1967-1980) Revista del Centro de Estudios de la Realidad Contemporánea, No. 6 (1988): 36-53. Web. 14 enero de 2015.

SEL, Susana. "Comunicación Alternativa y Políticas públicas en el combate Latinoamericano" Sel, Susana (Comp.) La comunicación mediatizada: hegemonías, alternatividades, soberanias. Buenos Aires: CLACSO, 2009, 13-35.

STERN, Steve J. Luchando por mentes y corazones: las batallas de la memoria en el Chile de Pinochet. Santiago: Eds. Universidad Diego Portales, 2013 [2006]. Print.

SUNKEL, Guillermo. El Mercurio: diez años de educación política-ideológica 1969-1979. Santiago: ILET, 1983.

TEITELBOIM, Volodia. "Intervención de Volodia Teitelboim en Asamblea de Artistas e Intelectuales del Partido Comunista" La revolución chilena y los problemas de la CULTURA. Santiago: Talleres Horizonte, 1971.

VALDÉS, Hernán. “¿Prudencia o desorientación para formular las bases de una política cultural? Cuadernos de la Realidad Nacional, No. 8 (Junio 1971):

VARELA, Mirta. "Intelectuales y Medios de Comunicación" Altamirano, Carlos (Dir.) Historia de los Intelectuales en América Latina. Buenos Aires: Katz, 2010.

ZAROWSKY, Mariano. "En torno al vínculo entre saber-político en los trabajos de Armand Michèle Mattelart en el periodo chileno" Cuadernos Crítico de Comunicación y Cultura, No. 2 (2007): 21-40.

ZAROWSKY, Mariano. Del Laboratorio chileno a la comunicación-mundo. Un itinerario intelectual de Armand Mattelart. Buenos Aires: Editorial Biblos, 2013.

\section{Notas}

1 Desde 1976, aparecieron revistas y radios que se declararon abiertamente disidentes a la dictadura. Estos soportes comunicacionales fueron claves para articular una oposición en el Espacio Público. A pesar de las restricciones impuestas y a la violencia desatada por la junta militar, las comunicaciones disidentes hicieron circular información distinta a la oficial a través de distintas estrategias comunicacionales. (Brunner, 1985; Stern, 2013 [2006]; Rivera, 2008; Santa Cruz, 2014).

2 Gutiérrez et. al., señalan que de esta manera: "La derecha abandona el discurso de aparente neutralidad y extraterritorialidad partidaria con que anteriormente había manejado a sus medios, para comenzar a elaborar discursos directamente partidarios y comprometidos con campañas de presión sicológica que cuentan con asesoría técnica calificada ("campaña del terror" y campaña de desestabilización). La Democracia Cristiana, intentando mantener el equilibrio y, a su vez, la distinción con el resto de los sectores. Y la izquierda, sin una clara identidad que los distinga del resto de los medios de masas que los instale en el proyecto de la Unidad Popular" (220). 
3 Los proyectos reformistas que se gestaron en las universidades nacionales están repletos de matices que los hacen ser particulares. Estas diferencias se pueden apreciar en los debates que se dan en este periodo en torno a la conceptualización de Universidad (Jaksic, 2008)

4 Entendemos por Comunicaciones Alternativas aquellos medios que luchan contra la dominación de los grandes conglomerados mediáticos y que se encuentran ligados al devenir de movimientos y grupos políticos.

5 Para contrastar con el proceso de la Universidad de Chile ver Jaksic, Ivan. "Chile" García G., Carmen. Pensadores y forjadores de las universidad latinoamericana. Venezuela: UNESCO-IESALC/ CENDES/Bio\&co., 2008. Huneeus, Carlos.La reforma en la Universidad de Chile. Santiago:CPU, 1988. Millas, Jorge. Ideas y Defensa de la Universidad. Santiago: Ediciones UDP, 2012.

6 Como señala Fernanda Beigel (2011), el Instituto de Sociología, fundado por el jesuita Rogers Veckemans, se caracterizó por ser un espacio de reflexión en temas de subdesarrollo y pobreza en el tercer mundo. Muchos de los profesores que ahí participaron, estaban relacionados con distintos espacios de formación política cristiana.

7 La participación del sociólogo Pascal Allende en el Centro fue de un año. Luego asumió un rol protagónico en la dirección del Movimiento Revolucionario de Izquierda (MIR).

8 Desde fines de los años cincuenta, las universidades latinoamericanas se abrieron al estudio del Marxismo. En el caso chileno, Vasconi señala que las tensiones sociales, el fortalecimiento de los movimientos obreros y campesinos asociados al FRAP y el marco de acción que dibujó el programa político de Revolución en Libertad, sentaron las condiciones para hacer de las Instituciones de Educación Superior, un espacio de discusión política-ideológica (Vasconi, s/f: 17-26)

9 Distintos autores concuerdan (Vasconi 1991; Beigel 2010; Beigel 2011; Lozoya 2013) que las redes que desarrollaron los académicos -todas distintas y muy variadas- fueron claves para la evolución teórica-conceptual. A las vinculaciones con los jesuitas a través del Centro para el Desarrollo Económico y Social de América Latina (DESAL), dirigido por Rogers Veckemans se suman las comisiones de poblamiento dirigidas por la Iglesia. Sin embargo, el paso decisivo será ICIRA, el cual contó con un equipo de académicos extranjeros en su mayoría brasileños que habían salido de su país como consecuencia del golpe de Estado militar de 1964 contra el presidente Goulart. Entre ellos destacan Paulo de Tarso Santos, Almino Affonso, Paulo Freire, Amadeu Thiago de Melo, Ernani Maria Fiori entre otros. Asimismo, la mayoría de estos intelectuales europeos, mantuvieron sus redes con el primer mundo lo que permitió una mayor recepción de nuevas teorías.

10 Siete profesores de planta asumen cargos en el gobierno de la Unidad Popular: José A. Viera Gallo, Sergio Politoff, Mabel Piccini, Armand y Michèle Mattelart, Tomás Moulian, Jaime Crispi y Jacques Chonchol.

$11 \mathrm{El}$ académico José Brunner señala enfáticamente que "independiente de los procesos internos, la reforma nunca paró, ni cambió su sentido" (Brunner, José J. Entrevista Personal, Noviembre, 15, 2014).

12 Cabe constatar que se consideraron todos los criterios de participación. Es decir, jornada, completa y media, profesor visitante, profesor asociado, profesor hora.

13 Esta investigación da origen a la publicación "La mujer chilena en una nueva sociedad. Un estudio exploratorio acerca de la situación e imagen de la mujer chilena”, Editorial del Pacífico, Santiago de Chile, 1968.

$14 \mathrm{El}$ contacto de los académicos Mattelart con el linguismo francés se gestó en el Centro ICIRA. Michel Utard, esposa de Rodrigo Ambrosio, fue la primera en facilitar un texto de Greimas. Su lectura determinó la línea de desarrollar posteriormente en el CEREN, lo cual queda evidenciado en la compra bibliográfica que realiza en Paris para construir un archivo bibliográfico por encargo del director Jacques Chochol. 
15 Como Director de Desarrollo Social de ICIRA, Mattelart con su equipo compuesto por René Eyheralde, Alberto Peña, Andrés Necochea, Leonardo y Carmen Castillo entre otros, habían comenzado a estudiar el impacto de las comunicaciones en una sociedad dependiente. En 1970, en co-autoria con Leonardo y Carmen Castillo, publicó La ideología de la dominación en una sociedad dependiente. La respuesta ideológica de la clase dominante chilena al reformismo.

16 La académica de la Universidad Nacional de Córdoba y esposa de Carlos S. Assadourian, Mabel Piccini, llega a Chile después del golpe en Argentina de 1966. Se vincula al equipo con el grupo de intelectuales Gramscianos de Argentina. Durante la Unidad Popular, milita junto al Movimiento de Izquierda Revolucionaria (MIR) al igual que otros colegas exiliados del Centro como, por ejemplo, el sociólogo desaparecido Patricio Biedman.

17 Fernanda Beigel señala que "El compromiso político de los cientistas sociales no era por otra parte, una illusio radicalmente nueva, sino bastante compatible con los ideales de las primeras generaciones de graduados de sociología, entre quienes no predominaba la "neutralidad valorativa" que tantas veces se ha utilizado para estigmatizar la llamada "sociología científica" (Beigel 2010 88). Si bien compartimos esta mirada, hay que destacar una transición mas marcada en el caso de la Universidad Católica. Desde la Reforma a la fecha de publicación del especial, la institución de educación superior y sus académicos se manifestaron comprometidos con las transformaciones sociales, pero ahora desde un compromiso político.

18 En 1973 la planta estaba compuesta por 23 investigadores, el 52\% eran militantes del Movimiento de Acción Popular Unitaria (MAPU), el 9\% del Movimiento de Izquierda Revolucionaria (MIR) y el $39 \%$ restante estaban afiliados a otros partidos de izquierda. Elaboración propia a partir entrevistas y registros biográficos.

19 Armand Mattelart asume como director del grupo de evaluación de recepción de las nuevas publicaciones, Michèle como parte del equipo de la revista Onda de Quimantú, y junto con Mabel como expertas en el departamento de guiones en Televisión Nacional. 